\title{
EFFECT OF A TWELVE WEEK EXERCISE PROGRAMME ON CARDIORESPIRATORY AND BODY COMPOSITION VARIABLES IN NONOBESE YOUNG AND MIDDLE-AGED FEMALES
}

\author{
GAIL M. WHITE* and R. J. YOUNG,† Ph.D. \\ *Smith College, Northampton, Massachusettes 01063 \\ tWashington University, St. Louis, Missouri 63130
}

\author{
Address correspondence to: \\ Dr. R. John Young, \\ Physical Education Department, Box 1067, \\ Washington University, \\ St. Louis, Missouri 63130
}

\section{ABSTRACT}

This study investigated the effect of a 12-week exercise programme consisting of jogging, calistnenics, and $\vec{N}$ recreational activities on the cardiorespiratory function and body composition of 15 young and 15 middle-aged nonobese women 21-32 and 34-57 years, respectively. The exercise programme was 3 days per week for an average of 45 minutes each session. Pre- and post-programme data were obtained on: age, height, total body weight, resting heart $\mathrm{O}$ rate, systolic and diastolic blood pressure, vital capacity, submaximal heart rate, supra-iliac skinfold, thigh skinfold, waist girth, cup size, body density, and percent fat. The t-test was used to test the difference between the young and middle-aged groups before and after the exercise programme and to test the pre-and post-programme mean values of each group. No differences between the groups or changes due to the exercise programme were observed on total body weight. No significant cardiorespiratory differences were found between the two groups at either test period, however, the young group decreased significantly $(p<.01)$ in submaximal HR and the middle-aged group decreased significantly in resting ( $p<.01)$ and submaximal $(p<.001)$ HR illustrating the positive effect of the programme. No significant body composition differences were found between the two groups at the pre-test. At the post-test the middle-aged group had a significantly $(p<.10)$ larger thigh skinfold thickness than the young group. The young group did not change significantly on body composition measures from pre- to post-test. In contrast, the middle-aged group increased significantly in body density $(p<.01)$ and decreased in percent body fat $(p<.01)$ due to a significant $(p<.01)$ reduction in supra-iliac skinfold thickness from $21.67 \pm 2.35$ to $18.13 \pm 2.08 \mathrm{~mm}$. The data were compared with data from other studies using similar age groups. The pre-test percent fat of the young group $(25.07 \pm .74)$ was similar to values reported in other studies. The middle-aged group had a relatively lower fat percentage $(27.46 \pm 1.58)$ compared with other middle-aged groups.

\section{INTRODUCTION}

Several studies have examined the cardiorespiratory (Eiseman and Golding, 1975; Fringer, 1973; Humphrey and Falls, 1975; Katch et al, 1973; McArdle et al, 1972) and body composition (Katch and Michael, 1968; Moody, 1972; Pollock et al, 1975; Sloan et al, 1962; Wade, 1976; Wallace, 1975; Wilmore and Behnke, 1971; Young et al, 1962) changes due to regular exercise in young untrained women. Few studies deal with the effect of exercise on physiological (Getchell and Moore, 1974) or body composition (Pollock et al, 1975; Young et al, 1963; Young, 1974) variables in nonobese middleaged women. This study, therefore, investigated the effect of a 12-week physical fitness programme on selected cardiorespiratory and body composition measures in nonobese young and middle-aged women.

\section{METHODS}

\section{Subjects}

Subjects were 30 women, 21 to 57 years, who partici- pated voluntarily in the Washington University Adult Physical Fitness Programme. Two discrete groups, consisting of 15 subjects each, were established and designated "young" (21 to 32 years) "and middle-aged" (34 to 57 years). All subjects had completed successfully a physical examination by their family physician before being admitted into the programme. Attendance was recorded at each meeting and each subject had at least 60 percent attendance.

\section{Exercise Programme}

The physical fitness programme consisted of three one hour sessions weekly for 12 weeks. It was designed to improve cardiovascular efficiency, muscular strength, muscular endurance, and flexibility. At each session subjects took part in: jogging for warm-up $(5 \mathrm{~min}$. maxi-

The experiments described in this paper were approved by the Committee on the Use of Human Subjects in Research at Washington University. The authors appreciate the assistance of Jody Rodewald and Rand L. Rosenthal in the collection of date. 
mum); calisthenics (20 min. maximum); jogging (20 min. maximum), and self-selected recreational activities (15 min. maximum). The programme was intensified progressively and consisted of individually prescribed exercise designed to elicit approximately 70 percent of maximal working capacity. The calisthenic exercises focused on flexibility, muscular strength, and muscular endurance and involved selected exercises performed in the standing, kneeling, sitting and lying positions. Following calisthenics each individual ran for a gradually increasing distance. The distance varied according to the ability of the individual but, at the conclusion of the programme, the distance range observed was between one and five miles. The recreational activities provided were swimming, weight-training, gymnastics, basketball, and soccer.

\section{General Testing Procedure}

Data were collected on all subjects in the first and final weeks of the programme. On each occasion they reported to the Exercise Physiology Laboratory where they rested quietly in the supine position for 10 minutes. Heart rate and systolic and diastolic blood pressures were measured using standard clinical procedures at the end of the 10 minute rest. In addition, height and weight were obtained, and vital capacity was determined using a basic spirometer module unit manufactured by Collins (model P-1253).

The subject then pedalled on a Quinton-Monark cycle ergometer for $5 \mathrm{~min}$. at a rate of $50 \mathrm{rev} . / \mathrm{min}$. (by a metronome) against a workload of $300 \mathrm{mkp} / \mathrm{min}$. (50W). Submaximal heart rate was recorded at the end of the fifth minute of exercise.

Pre- and post-test anthropometric measurements were obtained by the same female investigator. Skinfold fat was measured in $\mathrm{mm}$ by standard methods using a Lange skinfold fat calliper at the supra-iliac and front thigh. The calliper had a constant pressure of $10 \mathrm{~g} / \mathrm{mm}^{2}$ and measures were taken on the right side. Waist girth was measured in $\mathrm{cm}$ using a Lufkin steel tape. Brassiere cup sizes $A, B, C$ and $D$ were transformed into the numerical values of 1,2, 3 and 4, respectively. Body density was estimated using the predictive equation $(R=0.889, S E=$ 0.0069) of Pollock et al, 1975 as follows:

$$
\begin{aligned}
& \text { Density }(\mathrm{g} / \mathrm{ml})=1.1023-(\text { supra-iliac skinfold } 0.0005) \\
& \text { - (thigh skinfold 0.0003) - (waist } \\
& \text { girth } 0.0005 \text { ) - (cup size } 0.0033 \text { ). }
\end{aligned}
$$

Percentage fat was estimated by the formula of Rathbun and Pace, 1945 as follows:

$$
\text { Fat } \%=\frac{100(5.1350-4.6940)}{\text { Body density }}
$$

\section{Variables}

Pre- and post-programme data were collected on 15 cardiorespiratory and body composition variables. They were: age, height, total body weight (TBW), resting heart rate, systolic blood pressure, diastolic blood pressure, pulse pressure, vital capacity, submaximal heart rate, supra-iliac skinfold, thigh skinfold, waist girth, cup size, body density and percent fat.

\section{Statistical Analysis}

Student's t-test was used to compare the young and middle-aged groups before and after the exercise programme and to compare the pre- and post-test mean values of the young and middle-aged groups.

\section{RESULTS}

Personal data of the young and middle-aged groups at the pre- and post-test periods are presented in Table 1. No pre- or post-test differences between the groups or changes due to the exercise programme were observed

\begin{tabular}{|c|c|c|c|c|c|}
\hline \multirow{2}{*}{ Variable } & \multicolumn{2}{|c|}{ Pre-test } & \multicolumn{2}{|c|}{ Post-test } & \\
\hline & $\bar{x}$ & S.E. & $\bar{x}$ & S.E. & $\mathbf{t}$ \\
\hline \multicolumn{6}{|c|}{ Young $(n=15)$} \\
\hline Age (years) & 25.40 & .84 & 25.40 & .84 & \\
\hline Height $(\mathrm{cm})$ & 162.89 & 1.93 & 162.89 & 1.93 & \\
\hline Weight (kg) & 58.04 & 1.97 & 59.54 & 1.58 & \\
\hline
\end{tabular}
on total body weight (TBW).

\section{TABLE I}

Personal data

\section{Middle-aged $(n=15)$} (34.57 years)

Height $(\mathrm{cm})$ 43.47

Weight $(\mathrm{kg})$

161.11

1.67

60.84

2.11

$\begin{array}{ll}43.47 \quad 1.67 \\ 161.11 & 2.11\end{array}$

$161.11 \quad 2.11$

$61.05 \quad 1.87$

1.29

Cardiorespiratory data are presented in Table II to illustrate the effect of the exercise programme. The young group increased significantly in vital capacity $(p<$ $.05)$ and decreased $(p<.01)$ in submaximal HR and the middle-aged group decreased in resting $(p<.01)$ and submaximal $(p<.001)$ heart rates.

Body composition data are presented in Table III. No significant differences were found between the two groups at the pre-test. At the post-test the middle-aged group had a significantly $(p<.10)$ larger thigh skinfold 
than the young group. The young group did not change significantly on body composition measures from pre- to post-test. In contrast, the middle-aged group signific- antly reduced in supra-iliac skinfold thickness $(p<.01)$, के increased in body density $(p<.01)$, and decreased in $\underset{\mathbb{D}}{<}$ percent body fat $(p<.01)$.

TABLE II

Cardiorespiratory data of young and middle-aged groups

Variable

Young

Resting HR (beats/min)

Systolic BP $(\mathrm{mmHg})$

Diastolic BP $(\mathrm{mmHg})$

Pulse pressure $(\mathrm{mmHg})$

Vital capacity (L)

Submaximal HR (beats/min)

Middle-aged

Resting HR (beats/min)

Systolic BP $(\mathrm{mmHg})$

Diastolic BP $(\mathrm{mm} \mathrm{Hg})$

Pulse pressure $(\mathrm{mmHg})$

Vital capacity (L)

Submaximal HR (beats/min)

$\begin{aligned} * & \text { t-Ratio 2.15 }=p<0.05 \\ * * & \text { t-Ratio 2.98 }=p<0.01 \\ * * * & \text { t-Ratio 4.14 }=p<0.001\end{aligned}$

\begin{tabular}{rrrr} 
& Pre-test & \multicolumn{1}{c}{ Post-test } \\
& S.E. & $\bar{X}$ & S.E. \\
& & & \\
72.67 & 2.70 & 67.07 & 2.77 \\
118.00 & 3.68 & 118.67 & 2.81 \\
73.60 & 2.83 & 71.20 & 2.67 \\
44.40 & 2.29 & 47.47 & 1.98 \\
3.35 & .15 & 3.49 & .13 \\
123.60 & 4.47 & 110.87 & 3.63
\end{tabular}

$\begin{array}{rr}76.40 & 1.89 \\ 119.07 & 2.93 \\ 76.07 & 2.38 \\ 43.00 & 1.75 \\ 3.17 & .14 \\ 125.07 & 2.41\end{array}$

66.60

114.87

72.53

42.33

3.25

114.13
2.02

3.48

2.79

2.40

.14

2.60

TABLE III

Body composition data of young and middle-aged groups

Variable

Young

Supra-iliac skinfold $(\mathrm{mm})$

Thigh skinfold $(\mathrm{mm})$

Waist girth $(\mathrm{cm})$

Cup size

Body density $(\mathrm{g} / \mathrm{ml})$

Fat (\%)

\section{Middle-aged}

Supra-iliac skinfold $(\mathrm{mm})$

Thigh skinfold $(\mathrm{mm})$

Waist girth $(\mathrm{cm})$

Cup size

Body density $(\mathrm{g} / \mathrm{ml})$

Fat $(\%)$
Pre-test

$\mathbf{X}$

$\begin{array}{cc}19.17 & 1.29 \\ 42.93 & 1.88 \\ 69.42 & 1.58 \\ 2.00 & .24 \\ 1.0385 & .002 \\ 25.07 & .74\end{array}$

$\begin{array}{cc}21.67 & 2.35 \\ 46.70 & 2.58 \\ 73.10 & 2.30 \\ 2.20 & .24 \\ 1.0336 & .003 \\ 27.46 & 1.58\end{array}$

$\mathbf{x}$

17.00

40.70

69.19

2.07

1.0401

24.35

18.13

$46.03^{a}$

71.93

2.20

1.0362

26.24
S.E.

1.39

1.72

1.50

.23

.002

.78

2.08

2.13

1.86

.24

.003

1.39

Post-test

$\Delta$

$-2.17$

$-2.23$

$-0.23$

$+0.07$

$+0.0016$

$-0.72$

$-3.54$

$-0.67$

$-1.17$

$-$

$+0.0026$

$-1.22$

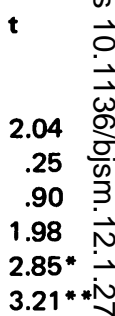

3.21 * *N

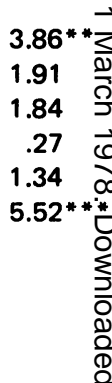

1.84

.27

34

52 *

3.87 * *

.37

$.91 \stackrel{\mathrm{D}}{\circ}$

$298 * * T$

$2.98 * * 0$

$3.07 * * \overline{\mathrm{T}}$

a Significantly different from young group $(p<.10)$

${ }^{*}{ }^{*}$ t-Ratio $2.98=(p<0.01)$ 
TABLE IV

Comparison of body composition results in young and middle-aged women

Investigator
Young
Sloan et al, 1962
Pollock et al, 1975
Novak, 1972
Getchell et al, 1977
Katch \& Michael, 1968
Young et al, 1962
Novak, 1972
Present study
Middle-aged
Lewis et al, 1976 *a
Pollock et al, 1975
Novak, 1972
Young, 1964
Novak, 1972
Present study*
*Pre-training values
**Estimated from data provided by authors
a Obese subjects

Comparison of the data from this study with data reported by other investigators (Table IV) revealed that the pre-test percent fat of the young group (25.07 \pm .74$)$ was similar to values reported in other studies. The middle-aged group had a relatively lower fat percentage (27.46 \pm 1.58$)$ compared with studies using subjects in the same age range.

\section{DISCUSSION}

This study investigated the effect of a supervised physical fitness programme on the cardiorespiratory function and body composition of nonobese young and middle-aged women. Significant reductions were found in submaximal HR, in the case of the young group, and resting and submaximal $H R$, in the case of the middleaged group reflecting improvements in cardiorespiratory function due to the exercise programme. Similar findings have been reported by Kilbom, 1971 and Drinkwater, 1973. No significant differences were found between the two groups at either test period on cardiorespiratory measures. Expected age differences were found on all measures collected. For example, lower blood pressure, lower heart rates, higher body density, and less body fat were associated with youth.

No pre- or post-test differences between the groups or changes due to exercise were observed on TBW, in fact, both groups increased slightly. This finding is not entirely surprising. Only slight reductions in mean TBW are seen in comparable studies on men (Boileau et al, 1971; Carter and Phillips, 1969; Dempsey, 1964; Glick and Kaufman, 1976) and it is not uncommon for TBW to increase slightly at the outset of an exercise programme before reducing after 3 to 4 months of regular exercise if diet is held constant. Some investigators report a reduction in the TBW of women as a result of exercise (Getchell and Moore, 1974; Lewis et al, 1976; Wallace, 1975; Zuti and Golding, 1973) while others have found no reduction (Girandola, 1976; Katch, 1969; Moody, 1972; Shire et al, 1977; Wade, 1976). Lewis et al, 1976 found that exercise reduced TBW by as much as $4.2 \mathrm{~kg}$ in a group of obese women with 40 percent body fat initially. The reduction in TBW in their study was more pronounced when the exercise programme was accompanied by a dietary programme. The subjects in this study were not obese as evidenced by the pre-test percent fat values of each group (young, 25.07 \pm .74 ; middle-aged, $27.46 \pm 1.58)$. They were instructed not to alter their normal diet but no record was kept to ensure their compliance.

The average percent body fat reported for nonobese young women is 22 to 29\% (Pollock et al, 1975) and 29 to $35 \%$ for middle-aged women (Pollock et al, 1975; Young et al, 1963). The young group in this study resembled young groups studied by other investigators (Getchell et al, 1977; Katch and Michael, 1962; Novak, 
1972; Pollock et al, 1975; Sloan et al, 1975; Young et al, 1962) but the middle-aged group was relatively lower in percent fat (Table IV). Not surprisingly there was no significant alteration in the body composition of the young group in this study, however, the middle-aged group increased significantly in body density and decreased significantly in percent fat due largely, it $₹$ would appear, to a reduction in supra-iliac skinfold thickness from $21.67 \pm 2.35$ to $18.13 \pm 2.08 \mathrm{~mm}$. These results suggest that a programme such as the one described in this paper can be effective in altering body composition in non-obese middle-aged women.

\section{REFERENCES}

Boileau, R. A., Buskirk, E. R., Horstman, D. H., Mendez, J. and Nicholas, W. C., 1971. "Body composition changes in obese and lean men during physical conditioning", Med.Sci.Sports, 3: 183-189.

Carter, J. E. L. and Phillips, W. H., 1969. "Structural changes in exercising middle-aged males during a 2-year period", $\vec{N}$ J.Appl.Physiol., 27: 878-894.

Dempsey, J. A., 1964. "Anthropometric observations in obese and nonobese young men undergoing a program of $\circ$ vigorous physical exercise", Research Quart., 35: 275-287.

Drinkwater, B. L., 1973. "Physiological responses of women to exercise", In: Exercise and Sports Sciences Reviews, edited by J. H. Wilmore, Academic Press, p. 125: New York.

Eiseman, P. and Golding L. A., 1975. "Comparison of effects of training on $\mathrm{VO}_{2}$ max in girls and young women", Med.Sci.Sports, 7: 136-138.

Fringer, M. N., 1973. "Relationships among selected cardiorespiratory variables in young adult females", Research Quart., 44: 448-457.

Getchell, L. H. and Moore, J. C., 1974. "Physiological response of middle-aged women to physical training", Med.Sci.Sports, 5: 75.

Getchell, L. H., Kirkendall, D. and Robbins, G., 1977. "Prediction of maximal oxygen uptake in young adult women joggers", Research Quart., 48: 61-67.

Girandola, R. N., 1976. "Body composition changes in women: effects of high and low exercise intensity", Arch.Phys.Med.Rehab., 57: 297-300.

Glick, Z. and Kaufman, N. A., 1976. "Weight and skinfold thickness changes during a physical training course", Med.Sci.Sports, 8: 109-112.

Humphrey, L. D. and Falls, H. B., 1975. “Circulatory and metabolic responses of young women at HR=180 and HR= max", Research Quart., 46: 498-504.

Katch, F. I. and Michael E. D. Jr., 1968. "Prediction of body density from skinfold and girth measurements of college $\widetilde{N}$ females", J.Appl.Physiol., 25: 92-94.

Katch, F. I., Michael, E. D. Jr., and Jones, E. M., 1969. “Effects of physical training on body composition and diet of females", Research Quart., 40: 99-104.

Katch, F. I., McArdle, W. D., Czula, R. and Pechar, G., 1973. “Maximal oxygen intake, endurance running performance, and body composition of college women", Research Quart., 44: 301-312.

Kilbom, A., 1971. "Physical training in women", Scand.J.Clin.Lab.Invest., 28: (Suppl. 119): 1.

Lewis, S., Haskell, W. L., Wood, P. D., Manoogian, N., Bailey, J. E. and Pereira, M., 1976. “Effects of physical activity on weight reduction in obese middle-aged women", Am.J.Clin.Nutr., 29: 151-156. 
McArdle, W. D., Katch, F., Pechar, G., Jacobson, L. and Ruth, S., 1972. "Reliability and interrelationships between maximal oxygen intake, physical work and step-test scores in college women", Med.Sci.Sports, 4: 182-186.

Moody, D. L., Wilmore, J. H. and Girandola, R. N., 1972. “Effects of a jogging program on body composition of normal and obese high school girls", Med.Sci.Sports, 4: 210-213.

Novak, L. P., 1972. "Aging, total body potassium, fat-free mass, and cell mass in males and females between ages 18 and 85 years", J.Gerontol., $27:$ 438-443.

Pollock, M. L., Laughridge, E. E., Coleman, B., Linnerud, A. C. and Jackson, A., 1975. "Prediction of body density in young and middle-aged women", J.Appl.Physiol., 38: 745-749.

Rathbun, E. D. and Pace, N., 1945. "Studies on body composition. I. The determination of total body fat by means of the body specific gravity", J.Biol.Chem., 158: 667-676.

Shire, T. L., Avallone, J. P., Boileau, R. A., Lohman, T. G. and Wirth, J. C., 1977. "Effect of high resistance and low resistance bicycle ergometer training in college women on cardiorespiratory function and body composition", Research Quart., 48: 391-400.

Sloan, A. W., Burt, J. J. and Blyth, C. S., 1962. "Estimation of body fat in young women", J.Appl.Physiol., 17: 967-970.

Wade, C. E., 1976. "Effects of a season's training on the body composition of female college swimmers", Research Quart., 47: 292-295.

Wallace, J. P., 1975. "Responses of the composition of body fat to cardiovascular training in college women", Research Quart., 46: 317-322.

Wilmore, J. H. and Behnke, A. R., 1971. "An anthropometric estimation of body density and lean body weight in young women", Am.J.Clin.Nutr., 24: 1186-1192.

Young, C. M., Martin, M., Tensuan, R. and Blondin, J., 1962. "Predicting specific gravity and body fatness in young women", J.Am.Dietet.Assoc., 40: 102-107.

Young, C. M., Blondin, J., Tensuan, R. and Fryer, J. H., 1963. “Body composition of 'older' women", J.Am.Dietet.Assoc., 43: 344.

Young, C. M., Blondin, J., Tensuan, R. and Fryer, J., 1963. "Body composition studies of 'older' women, thirty to seventy years of age", Ann.N.Y.Acad.Sci., 110: 587-607.

Young, C. M., 1964. "Prediction of specific gravity and body fatness in older women", J.Am.Dietet.Assoc., 45: 333-338.

Zuti, W. B. and Golding, L. A., 1973. "Effects of diet and exercise on body composition of adult women during weight reduction", Med.Sci.Sports, 5: 62. 